УДК 330.101.542:334

DOI: $10.21779 / 2500-1930-2017-32-4-26-31$

\title{
Ф.3. Mexdu
}

\section{Развитие предпринимательской деятельности в инновационной среде}

Азербайджанский государственный университет нефти и промышленности; Азербайджан, AZ1010, Баку, пр. Азадльг,,16/21; farid.mehdi2@gmail.com

В современный период инновации являются основой деятельностной миссии репутационной организации. Вместе с тем развитие инновационного предпринимательства служит не только целью рейтинга фирмы. Это постоянно совершенствующийся, подвижный организационный инструмент, направленный на овладение рыночной конъюктурной и защиту ее устойчивого развития. Следовательно, в зависимости от сферы промышленности в рамках развития инновационного предпринимательства следует разработать систему конкретных мер и реализовать их. При этом наряду с самими предпринимателями заботу и поддержку должно оказать и государство.

Ключевые слова: инновационная предпринимательская деятельность, экономическая стратегия, перспективы развития, научно-интеллектуальный потенциал, анализ бизнесcpedbl.

Главные достижения в условиях рыночной экономики - увеличение производительности труда и рост прибыли в иннвационном предпринимательстве как один из способов конкурентной борьбы. В рыночной конкуренции победителем выходит тот кто в должного момент достигает необходимого прорыва на основе применения прогрессивных технологий. Согласно сформулированным теоретическим положениям субъектами инновационного предпринимательства являются предприятия и организации, которые реализуют инновационную деятельность.

По мере развития экономики понятие инновации также приобретает более широкий смысл. Если раньше инновация ограничивалась лишь технологической сферой, то теперь сюда входят и организационные методы в управлении производством. Все это на основе симбиоза с предпринимательской деятельностью превратило их в наиболее активную и интеллектуальную сферу бизнеса.

В период инновационного предпринимательства формируются новые требования. Исходя из них, покупатели не хотят приобретать устаревшие товары. Работа, которая ведется в целях улучшения видов товаров, проявляет динамику качества, будучи направлена в сторону постоянной смены имиджа и развития.

Любая инновационная деятельность носит предпринимательский характер и включает в себя:

- поиск необходимых ресурсов;

- формирование организации и управление ею;

- достижение личностных результатов с финансовой прибылью.

Вместе с тем не каждая предпринимательская деятельность может считаться инновационной. Здесь исключены те виды деятельности, которые получают предпринимательскую прибыль через диффузию продукта и его использование [1].

В нефтяной промышленности инновационное предпринимательство является динамичным процессом и играет существенную роль как в технологическом, так и управленческом контексте. В Азербайджанской Республике, которая реализует новую 
нефтяную стратегию на основе большого карбогидрогенного потенциала, также есть большая потребность в расширении инновационной деятельности.

Известно, что технологическая и экономическая стратегии, применяемые при освоении нефтяных структур Каспия, обладающих большим потенциалом, основаны на инновационной деятельности. Следует отметить, что в разработке новых месторождений участники консорциума в целом применяют самые современные и передовые технологии, прикладывая серьезные усилия для развития инновационного предпринимательства. На самом же деле здесь все еще присутствуют виды предпринимательской деятельности, имеющие консервативную систему управления в виде замкнутого круга и со слабым потенциалом развития.

Инновации, применяемые здесь, потребляются вне пределов республики в достаточно широком диапазоне. Сторонники консорциума, учитывая, что производственные и служебные предприятия, действующие в составе азербайджанской нефтяной структуры, не соответствуют универсальным стандартам и не обладают соответствующими монограммами, решили осуществлять инновационную деятельность за счет ресурсов евро-атлантического пространства. Разумеется, подобный подход значительно ограничивает инновации в нефтяном секторе, основанном на деятельности местных предпринимателей.

Прежде чем обстоятельно анализировать формирование, современное состояние и перспективы развития инновационной деятельности в азербайджанской нефтяной промышленности, необходимо определить сущность и принципы предпринимательской деятельности с точки зрения современных требований. Это прежде всего связано с необходимостью научного обоснования направления и модели развития инновационного предпринимательства в азербайджанской нефтяной промышленности.

Инновационная деятельность, являясь многоаспектной сферой экономической деятельности, обеспечивает участие в усвоении нового продукта как физических, так и юридических лиц. В нефтяном секторе инновационные продукты формируются аналогичным образом. Инновационная деятельность, являясь широкой и развлетвленной, обусловливает создание сообтветстующей инфраструктуры. В сеть этой инфраструктуры входят пять существенных элементов:

- нормативно-правовая база;

- организационная сеть, реализующая коммерциализацию и капитализацию научных разработок;

• консультационные центры;

• центры по передаче информации;

- организации, реализующие экспорт и импорт вновь создаваемой продукции [3].

Положение сети детерминантов, ограничивающих инновационное предпринимательство в национальном нефтяном секторе, на самом деле не является сложной или трудной системой. Исследования доказали, что широта деятельности в нефтяном секторе во всех направлениях, формирование деловой бизнес-среды напрямую связаны с совершенствованием нормативно-правовой базы. В этой сфере в стране ежегодно проводится соответствующая работа. Однако есть потребность ускорения проводимых работ. В законодательной сфере надо совершенствовать работу с учетом перспектив.

Ясно, что организационная сеть, реализующая коммерциализацию и капитализацию научных разработок квалифицированных специалистов - инженеров, выпускников вуза, получившего звание первой Нефтяной академии, соответствующие центры консалтинга и передачи информации, организации, реализующие импортно-экспортные операции, будут сформированы и добьются высокого рейтинга в своей деятельности 
[2]. Важными условиями усиления данного процесса являются проведение в жизнь адекватной государственной инновационной политики и расмотрение данной политики в рамках долгосрочных программ.

В связи с вышеуказанным следует обратить внимание на то, что инновационный процесс опирается на инновационную деятельность общества в целом. Он выступает как совокупность интеллектуального труда при создании нового продукта. Новый же продукт может носить технический, производственный или коммерческий характер. Указанные признаки можно полностью отнести и к нефтяному сектору.

Инновационный процесс - это процесс, который придает технике новые качества, меняет ее качественные параметры, более полно выражает общественные и личностные потребности.

Анализ показывает, что опыт использования нефтяных доходов в контексте инновационного предпринимательства может быть как успешным, так и неудачным. Успешная деятельность в этой области имеется в Норвегии, а неудачная - в Нигерии. Опыт этих стран еще раз продемонстрировал, что новаторский подход к хозяйственному процессу играет очень важную роль. Норвегия, будучи аграрной страной, при рациональном использовании богатых нефтяных месторождений очень быстро развила промышленные отрасли.

Норвежская модель успеха основана на всестороннем развитии инновационного предпринимательства. В Нигерии наблюдатель отрицательные проявления. Внешняя задолженность Нигерии, расположенной среди нефтяных гигантов, в результате ограниченного использования нефтяных доходов для предпринимательства, особенно инновационного, значительно возросла. Бедность и нищета в стране, богатой нефтяными ресурсами, амбиции государственных служащих и коррупция привели к тому, что экономика страны оказалось в кризисной ситуации. Напомним, что нефтяной сектор в обеих странах в основном находится в государственной монополии. Тем не менее, Норвегия всегда интересовалась развитием инноваций, а в Нигерии преобладал интенсивный и экстенсивный рост доходов без учета реальности [10].

Многочисленные предложения по рационализации, сделанные нефтяниками, геологами и учеными Азербайджанской Республики, содержат передовые промышленные образцы, технологические ноу-хау и другие нематериальные активы, которые широко используются в нефтяной промышленности. Чтобы проиллюстрировать это, достаточно рассмотреть научный и интеллектуальный потенциал страны. Главная проблема здесь заключается в финансовых ресурсах [11].

Анализ показывает, что нетрудно добиться успеха в технологической модернизации нефтяного сектора, а также в развитии отраслевой науки за счет использования имеющихся финансовых ресурсов, научно-технического и кадрового потенциала. Поэтому повышение государственной заботы о развитии науки является важным фактором для применения инноваций в нефтяном секторе.

Нефтяная компания, занимающаяся инновационным бизнесом, должна прежде всего разработать концепцию развития бизнеса. Для этого необходимо проанализировать бизнес-среду и оценить текущую ситуацию. Соответствующие процессы во всех трех измерениях деловой активности - малого, среднего и крупного бизнеса должны основываться на стратегическом планировании развития инновационного предпринимательства в нефтяной промышленности.

Функция стратегического планирования для развития инноваций в нефтяной промышленности важна в интерактивной форме, а именно на фоне переработки на 
каждом этапе. С этой точки зрения взаимосвязь между этапами процесса интерактивности должна быть более концептуальной, нежели реалистичной [9].

Малые инновационные компании являются основой инновационного предпринимательства. Эти фирмы становятся лидерами технологий в тех областях, где формируются новые рыночные сегменты экономики. Они создают новые технологические основы, уделяя основное внимание их элитарности и конкурентоспособности. В этом отношении формирование малых инновационных фирм для развития инновационного предпринимательства в нефтяной промышленности имеет первостепенное значение.

Практическая реальность такова, что у малых и частично средних инновационных предприятий есть шанс получать более высокую прибыль, чем у крупных предприятий. Это может быть обосновано следующим образом:

- стратегии, ориентированные на малый рынок;

- ограничение круга острой конкуренции;

- высокая капиталоемкость;

- благоприятность прямого доступа к потребителям.

Учитывая все это, расширение деловой активности в нефтяном секторе страны, а следовательно, и увеличение за этот счет экономической активности сферы, может быть рассмотрено в контексте организации малых предприятий нефтяного бизнеса [8].

Следует отметить, что стратегическая линия инновационного предпринимательства, свойственная вертикально интегрированному предпринимательству, может быть применена к любому сегменту малого и среднего бизнеса. Однако важно иметь более короткий срок службы соответствующего типа бизнеса [6]. Здесь эффективность связана с экономической нагрузкой инновационных продуктов, которая влияет на материальные и энергетические издержки, заработную плату, себестоимость, прибыль, запасы, рентабельность и все технические и экономические показатели.

Развитие инновационного предпринимательства связано с научно-техническим потенциалом области, качественными и количественными параметрами. Состояние и качество исследовательской деятельности определяются высококвалифицированным персоналом, изобретательностью, предпринимательством, информационным обеспечением, эргономической ситуацией, передовой системой управления и финансовыми возможностями. Конечно, комплексный подход к проблеме требует анализа других технико-организационных факторов [4].

Важно сосредоточить научные достижения в едином институте из всех существующих исследовательских организаций, чтобы повысить их способность получать доход как на местном уровне, так и за рубежом, а также создавать научно-исследовательские конструкторские бюро на крупных предприятиях. Необходимо реорганизовать традиционные лаборатории по научно-исследовательским и производственным направлениям, поскольку указанные научные и исследовательские учреждения утратили свою традиционную сущность и морально устарели.

Установление новых экономических отношений требует от этих учреждений активизации структуры и стратегии в соответствии с рыночно ориентированной системой. В этой связи многие глобальные компании и исследовательские центры расширяют свою сеть продуктивных научно-исследовательских услуг с помощью высококачественных продуктов, которые гибко трансформируются, уделяя особое внимание их материальному и научному потенциалу. Это качество, несомненно, приводит к развитию инновационного предпринимательства [5].

Таким образом, проведенный анализ показал, что развитие инновационного предпринимательства является важным для каждой страны. Реализация указанных меро- 
приятий даст высокие результаты, которые приведут к следующим качественным изменениям:

- становление и развитие нового амплуа инновационного предпринимательства в производственной и финансовой сферах;

- усиление зарубежного инвестиционного потока;

- совершенствование нормативно-правовой базы;

- расширение информационной аналитической сети;

- централизация научно-исследовтельских учреждений;

- создание научно-конструкторских бюро на крупных хозяйственных субъектах.

\section{Литература}

1. Грачева М. В. Инновационная деятельность в промышленности: теория и практика в странах рыночной экономики и инновационные опросы российских предприятий. - М.: ИМЭМО РАН, 1994. - 421 с.

2. Максимов Т.А. Инновационный характер процессов модернизации // Креативная экономика. - 2012. - Т. 6, № 5. - С. 9-13.

3. Тодосийчук $A$. О совершенствовании условий инновационной деятельности // Экономист. - 2010. - № 12. - С. 4-9.

4. Войтов А.Г. Экономика. - М.: Маркетинг, 2000. - 584 с.

5. Сэмюэльсон П.Э., Нордхаус В.Д. Экономика. - М.: Вильямс, 2000. - 688 с.

6. Экономика / под ред. А.С. Булатова. - М.: Юристь, 2013. - 896 с.

7. Рыжова Л.И. Основные элементы организации внутрифирменного бюджетирования на предприятиях отрасли коневодства. // Вестник Поволжского государственного технологического университета. - Йошкар-Ола - 2014. - № 1. - С. 86-94.

8. Сайфуллина С.Ф., Усманова 3.Я. Признаки инновационной экономики // Инновационная наука. - 2015. - № 12-1. - С. 264-266.

9. Дасковский В.Б. Особенности оценки эффективности инвестиций в экономике переходного периода // Пищевая промышленность. - 2005. - № 2. - С. 16-20.

10. Сухарев O., Нешитой $A$. Интеллектуальный потенциал и его неиндустриальное воспроизводство // Экономист. - 2011. - № 10. - С. 7-14.

11. Кравеи А.В. Инновационная экономика России: проблемы и перспективы экономического роста // Креативная экономика. - 2016. - Т. 10, № 1. - С. 21-34.

Поступила в редакиию 14 июня 2017 г. 
UDC 330.101.542:334

DOI: $10.21779 / 2500-1930-2017-32-4-26-31$

\section{Development of the entrepreneurial activity under environment of innovations}

\section{F.Z. Mehdi}

Azerbaijan State Oil and Industrial University; Azerbaijan, AZ1010, Baku, Azadlyg av., 16/21; farid.mehdi2@gmail.com

Nowadays, innovations are the basis in the activity mission of a reputational organization. At the same time, the development of the innovative entrepreneurship is not only the goal of the company reputation, it is a constantly improving, mobile organizational tool aimed at mastering the market conjecture and protecting its sustainable development. Consequently, it is recommended to develop and implement the system of definite measures, within the framework of the innovative entrepreneurship development. In this case, alongside the entrepreneurs themselves, the state should also provide care and support.

Keywords: innovative entrepreneurial activity, economic strategy, development prospects, scientific and intellectual potential, business environment analysis.

Received 14 June, 2017 